\title{
US65-OFR- $-95-433$
}

Optical, Noncontact, Automated Experimental Techniques for ThreeDimensional Reconstruction of object Surfaces Using Projection Moire, stereo Imaging, and Phase-Measuring Profilometry

By Jaime F. Cardenas-Garcia and Gary R. Severson

Abstract

\section{RECEIVED} MAY 221998

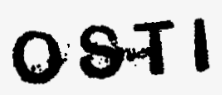

Three optical, noncontact, automated experimental téchniques for determining the topography of object surfaces were assessed. The main objective was to test the limitations of three experimental techniques: projection moire, stereo imaging, and phase-measuring profilometry. Phase-measuring profilometry is the most promising of the three techniques for mapping rock fracture surfaces automatically, accurately, quickly, and with high resolution. The experimental set-ups used to assess these different techniques are similar, and they require essentially the same equipment. It is relatively easy and inexpensive to go from one experimental set-up to another. Also, the experience gained in implementing one experimental technique is often applicable in another, although the basic principles of each experimental technique are sometimes very dissimilar.

The first technique, projection moire, is an optical experimental technique that is useful for displaying and measuring the three-dimensional form of large objects. Manual anplysis of 


\section{DISCLAIMER}

This report was prepared as an account of work sponsored by an agency of the United States Government. Neither the United States Government nor any agency thereof, nor any of their employees, makes any warranty, express or implied, or assumes any legal liability or responsibility for the accuracy, completeness, or usefulness of any information, apparatus, product, or process disclosed, or represents that its use would not infringe privately owned rights. Reference herein to any specific commercial product, process, or service by trade name, trademark, manufacturer, or otherwise does not necessarily constitute or imply its endorsement, recommendation, or favoring by the United States Government or any agency thereof. The views and opinions of authors expressed herein do not necessarily state or reflect those of the United States Government or any agency thereof. 
experimental moire data is tedious and time consuming; therefore, calibration of the experimental set-up, determination of the fringe number, phase measurement at a point, and distinction of concavity and convexity of a surface were automated in these studies. Also, estimates of the error for simply shaped objects were obtained. For the second technique, two stereo-imaging experimental set-ups that are useful in measuring the three-dimensional geometry of objects were studied: a parallel optical-axis model and a converging optical-axis model. Digital image correlation was used to find the disparities between corresponding points in a pair of images for each of these models with subpixel accuracy. To show the application of the developed algorithms and the stereo-imaging experimental set-ups, four different object surfaces were studied. For some of the objects, a higher measuring accuracy was obtained from a converging optical-axis experimental set-up. For the third technique, a new, fast, phase-measuring profilometer for full-field three-dimensional shape measurement was developed. Compared to other optical methods for three-dimensional shape measurement, this technique is faster and more accurate. The technique is based on the principle of phase measurement of a projected grating image on the object surface that conforms to the shape of the object. This deformed grating pattern carries the three-dimensional shape information of the surface to be measured. Six different kinds of surface shapes were measured with this experimental technique. The measurement error was less than 0.15 percent. For the objects used, the resolution reached 50 microns. 


\section{M98005232}

|||||||||||||||||||||||||||||||||||||||||||||||||||||||||

Report Number (14) USGS - OFR- $-95-433$

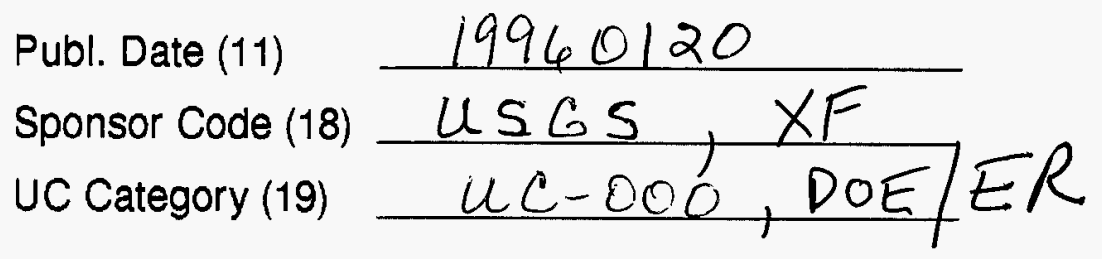

